\title{
Conflitos éticos na comunicação de más notícias em oncologia
}

Fátima Geovanini ${ }^{1}$, Marlene Braz ${ }^{2}$

\section{Resumo}

Partindo de abordagem qualitativa, com entrevistas semiestruturadas, analisadas pelo método hermenêuticodialético, busca-se identificar os conflitos éticos vividos por oncologistas na comunicação de diagnósticos de câncer, analisando os problemas desencadeados pelas más notícias. Da pesquisa participaram quinze oncologistas clínicos e cirurgiões, que relataram que a comunicação do diagnóstico de câncer é considerada difícil tarefa devido à ausência de investimentos para o desenvolvimento das habilidades de comunicação na graduação médica; ao simbolismo do câncer; à presença de fantasias relacionadas ao conhecimento do diagnóstico e a dificuldades na abordagem da morte. Os principais conflitos éticos citados estão relacionados à justa adequação moral do emprego da verdade na comunicação, se esta é uma ação beneficente para o paciente, e ao manejo com a família na relação médico-paciente. A conclusão observou que os problemas éticos desencadeados decorrem, predominantemente, em relações paternalistas com interferência na autonomia do paciente. Palavras-chave: Neoplasias. Relações médico-paciente. Revelação da verdade. Ética. Paternalismo. Autonomia pessoal.

\section{Resumen \\ Conflictos éticos en la comunicación de malas noticias en oncología}

Desde un enfoque cualitativo con entrevistas semiestructuradas, analizadas por el método hermenéutico dialéctico, se busca identificar los conflictos éticos vividos por oncólogos en la comunicación de diagnósticos de cáncer, analizando los problemas éticos provocados por las malas noticias. Participaron de la investigación quince oncólogos clínicos y cirujanos que reportaron que la comunicación del diagnóstico de cáncer como una tarea difícil de realizar debido a la falta de inversiones para el desarrollo de habilidades de comunicación en el pregrado de medicina; al simbolismo del cáncer; a la presencia de fantasías relacionadas con el conocimiento del diagnóstico y ; a las dificultades en el planteamiento de la muerte. Los principales conflictos éticos citados están relacionados con la justa adecuación moral del empleo de la verdad en la comunicación, si dicha acción es beneficiosa al paciente y al manejo con los familiares en relación médico-paciente. Se concluye que los problemas éticos que se desencadenan derivan, predominantemente, en relaciones paternalistas con interferencia en la autonomía del paciente.

Palabras-clave: Neoplasias. La relación médico-paciente. La revelación de la verdad. Ética. Paternalismo. La autonomía personal.

\section{Abstract \\ Ethical conflicts in communicating bad news in oncology}

Identifying difficulties and ethical conflicts experienced by oncologists in communicating cancer diagnostics, by analyzing ethical problems caused by bad news communication. A qualitative approach was chosen, by conducting semi-structured interviews, which were analyzed based on the hermeneutic-dialectic method. Fifteen oncologists, surgeons and physicians took part of this research. Diagnostic communication of cancer was assessed as a difficult task to be performed due to the lack of investments for the development of communication skills in medical schools; the symbolism of cancer, the presence of unreality related to the knowledge of the diagnosis and the difficulties in dealing with death. The main ethical conflicts cited are related to moral suitability of using truth in the communication to be established with the patient, if this action is a benefit for him and the medical management of the relationship with the patient's relatives. The ethical problems trigged are the predominance of paternalistic relationship and the interference in the autonomy of the patient. Key words: Neoplasms. Physician patient relationship. Truth disclosure. Ethics. Paternalism. Personal autonomy.

Aprovação CEP/ENSP 36/10

1. Doutoranda f.geovanini@hotmail.com 2. Doutora braz2@globo.com - Escola Nacional de Saúde Pública Sérgio Arouca/Fiocruz, Rio de Janeiro/RJ. Brasil. 
O câncer é considerado um problema de saúde pública, apresentando hoje significativo aumento tanto nos países desenvolvidos como nos em desenvolvimento. Mantendo-se como a mais importante causa de morte no mundo, parte de seu crescimento pode ser atribuído ao crescente envelhecimento populacional, além de também estar associado às mudanças de comportamento de vida e de consumo, bem como à urbanização acelerada ${ }^{1}$.

Dados estatísticos apontam para a gravidade do câncer, reafirmando os conteúdos simbólicos e imaginários que lhe são atribuídos. Trata-se de uma doença comumente relacionada à perda da integridade de seu portador, às mutilações físicas e, por fim, à finitude da vida. Por isso, o universo simbólico utilizado para se referir ao câncer é, em geral, permeado de significantes que evocam conteúdos de cunho negativo, sendo seu tratamento comumente associado à linguagem bélica ou militar, revelando dessa forma o estado de guerra que marca o período de tratamento e tentativa de remissão da doença ${ }^{2}$.

Considera-se pertinente afirmar, portanto, que em oncologia notícias difíceis são constantemente transmitidas, tanto na fase inicial como no estágio terminal da doença, demandando do médico oncologista o desenvolvimento de habilidades voltadas para a comunicação de diagnósticos e de prognósticos difíceis ${ }^{3}$. De acordo com Baile e colaboradores ${ }^{4}$, considera-se más notícias qualquer informação que afete de forma radical e definitivamente a perspectiva de futuro de quem a recebe.

Destaca-se neste artigo a diferença entre informar e comunicar diagnósticos e prognósticos de câncer. Entende-se que o ato de informar está relacionado ao momento inicial de revelação da doença, do tratamento ou do prognóstico. Contudo, considera-se que todas as informações devem estar inseridas no processo relacional de comunicação entre o médico, o paciente e a família, perpassando os diversos estágios enfrentados pelo doente, do início ao desfecho final do tratamento e da doença. Dessa forma, amplia-se o sentido do termo comunicação associando-o ao suporte contínuo aos profissionais e à ideia de compartilhamento entre todos os envolvidos ${ }^{5-7}$. Entende-se que dificuldades de comunicação podem ocorrer em qualquer situação relacional, especialmente em discussões nas quais estejam envolvidas questões de doença e de morte, sendo, no caso específico da oncologia, agravadas não apenas pelo simbolismo da palavra câncer, mas também pelas limitações de ordem pessoal e pela falta de reflexão e preparo do profissional designado para a realização dessa tarefa ${ }^{2,8,9}$.
Durante muito tempo, dificuldades dessa ordem contribuíram para a ocultação da verdade, para o emprego da mentira ou mesmo do silêncio na relação médico-paciente oncológico, estabelecendose esse padrão de comportamento como sendo moralmente correto ${ }^{10,11}$. Acredita-se que esse modelo relacional ainda esteja presente na atualidade; no entanto, mudanças na sociedade, com o desenvolvimento de novas tecnologias de informação, e no campo biomédico, com o acelerado aprimoramento das ciências médicas e o surgimento da bioética, podem estar contribuindo para a reformulação de paradigmas no campo da saúde, em que ganham destaque novos valores e regras morais associados à autonomia e à valorização do paciente na realização de seus desejos e no exercício de seus direitos ${ }^{3}$.

Confirmando essas mudanças, Beauchamp e Childress ${ }^{12}$ atentam para o fato de que, no contexto da ética médica contemporânea, as virtudes da sinceridade e da honestidade são consideradas de alto valor no caráter dos profissionais da área da saúde. Para que o paciente possa participar ativamente das tomadas de decisões a respeito de seu tratamento, torna-se imprescindível estar ciente da doença que o acomete, sua gravidade e possível evolução, e os benefícios e malefícios dos tratamentos disponíveis.

Considera-se que grande parte das mudanças surgidas no campo biomédico, sem desconsiderar os avanços farmacológicos, esteja centrada nas transformações ocorridas na relação médico-paciente, especialmente no que se refere ao lugar que a verdade ocupa nessa relação. O incentivo à ocultação da verdade e à mentira, considerada branda pela intenção de não provocar dano ao paciente, era presente nos tradicionais códigos de ética médica do século XIX. Um século depois as orientações estão voltadas para a honestidade com o doente, destacando o direito do paciente ao conhecimento de seu estado clínico atual ${ }^{13}$. No Código de Ética Médica brasileiro, em vigor desde abril de 2010, embora não seja possível observar novas orientações quanto à comunicação de diagnósticos e prognósticos, em comparação com o código de 1988, identificamos a ênfase atribuída ao exercício da autonomia do paciente ${ }^{14}$.

Nesse contexto de importantes mudanças sociais, com repercussões nas relações entre profissionais e pacientes, acredita-se que ao médico venha sendo imputado o desafio de adotar novas condutas, até então pouco exigidas pela sociedade ${ }^{3}$. Dificuldades surgidas pelo novo lugar que o paciente ocupa na relação médico-paciente e a forma como o médico foi treinado para atuar podem desencadear conflitos éticos a serem enfrentados pelo oncologis- 
ta, especialmente no momento de revelar informações acerca da doença oncológica e sua evolução.

Esta pesquisa teve como foco identificar as dificuldades e os conflitos éticos enfrentados pelos médicos oncologistas na comunicação de diagnósticos e prognósticos de câncer, tanto na fase inicial como no estágio terminal da doença, e também analisar os problemas éticos desencadeados pela qualidade da comunicação de más notícias e pelo conteúdo informado.

\section{Método}

Optou-se pela abordagem qualitativa, de cunho exploratório, tendo como instrumento de pesquisa a entrevista semiestruturada. A amostra foi composta por 15 médicos oncologistas, de ambos os sexos, com residência, especialização ou pós-graduação em oncologia clínica ou cirúrgica, atuando na cidade do Rio de Janeiro durante o ano de 2010.

A seleção dos participantes foi feita mediante indicação de profissionais da área da oncologia pertencentes ao círculo de confiança dos entrevistados e do pesquisador ${ }^{15}$. Oncologistas pediatras não foram incluídos nesta pesquisa, devido à especificidade do público infantil que não contemplava os objetivos deste estudo.

As entrevistas foram realizadas com oncologistas graduados em medicina em épocas distintas, redundando na participação de profissionais de diferentes gerações, abarcando de quatro a 47 anos de formação médica. Dentre os participantes da pesquisa, dez oncologistas atuam concomitantemente na rede pública e privada, sendo que nove deles fazem parte do quadro funcional de importante centro de referência no atendimento a pacientes com câncer na cidade do Rio de Janeiro.

Para a análise das falas foi utilizado o método hermenêutico-dialético, buscando estabelecer uma escuta que, para além do dito e nas entrelinhas do discurso, revelasse as contradições e os conteúdos não manifestos, característicos desta prática social.

\section{Resultados}

Esta pesquisa revelou diversos aspectos manifestos no cenário das relações médico-paciente oncológico, caracterizando as dificuldades afloradas nesse campo, especialmente quando se trata do difícil enfrentamento e do impacto que os médicos oncolo- gistas sofrem ao longo do processo de comunicação de más notícias aos pacientes e aos seus familiares - mais notadamente na fase de avanço da doença. Embora o eixo central desta pesquisa seja a comunicação, cabe relatar que, por tratar-se de tema inserido em cenário de tamanha complexidade, outros desdobramentos temáticos foram desencadeados e emergiram no discurso dos entrevistados, demandando a extensão do trabalho de escuta, interpretação e análise ao longo da elaboração da dissertação.

No entanto, para cumprir o objetivo deste artigo, serão apresentados exclusivamente os dados levantados referentes às dificuldades e aos conflitos éticos vividos pelos oncologistas no momento da revelação dos diagnósticos e prognósticos, enfocando as questões relacionadas ao conteúdo da informação transmitida, ao lugar da verdade na comunicação e ao manejo do médico na relação com a família do paciente.

\section{A comunicação do diagnóstico e os conflitos éticos}

Entre os oncologistas entrevistados, observouse importante preocupação no desenvolvimento de uma boa relação médico-paciente, considerada fundamental para a condução do tratamento. A comunicação do diagnóstico e do prognóstico de câncer foi avaliada como tarefa difícil, sendo sua boa condução determinante para a qualidade da relação estabelecida com os pacientes e seus familiares. Dentre os principais fatores atribuídos pelos participantes como os responsáveis pelas dificuldades na comunicação de más notícias, destacam-se: a ausência de investimentos para o desenvolvimento das habilidades relacionais e de comunicação nos currículos da graduação médica; as representações sociais e o simbolismo da doença oncológica; a presença de fantasias relacionadas ao conhecimento do diagnóstico e as dificuldades para lidar com a finitude da vida.

Os principais conflitos éticos citados pelos entrevistados estão relacionados à justa adequação moral do emprego da verdade na comunicação a ser estabelecida com o paciente e ao manejo da relação médica com os familiares do doente. A questão que se estabelece é se o ato de revelar a verdade diagnóstica constitui ou não ação beneficente para o paciente. O medo de que o conhecimento da doença desencadeie a piora do estado físico e emocional do paciente, aliado às demais dificuldades acima citadas, contribui para que a revelação do diagnóstico e, mais especialmente, dos prognósticos com rápida evolução não seja realizada de forma clara e objetiva. Predomina, então, o discurso que não contempla 
toda a verdade, repleto de omissões e meias verdades - tal como foi o comportamento padrão observado no século passado $3,10,11$.

No entanto, para os médicos participantes desta pesquisa, isso vem se caracterizando como um conflito, pois diante das mudanças contemporâneas desenvolvidas nos campos social e médico não mais se sentem à vontade para agir de tal forma. De acordo com o discurso analisado, o médico muitas vezes já consegue avaliar que sua conduta está errada, mas, em contrapartida, não se encontra ainda adequadamente preparado e com condições para agir de forma diferente. Com isso, encontra-se ainda presente na prática dos oncologistas a transmissão de informações pouco esclarecedoras, com conteúdos que não contemplam a verdade da doença, seu tratamento e prognóstico. Além dessas omissões presentes no discurso, pôde-se constatar a presença de conteúdo enganoso, comumente conhecido como "mentira piedosa" ${ }^{16}$.

Contribuindo para intensificar esse conflito, há dificuldades do oncologista no trato com os familiares do paciente. Na doença oncológica, a família mostra-se especialmente presente, estabelecendo com o doente uma relação de proteção na tentativa de poupá-lo de todo tipo de sofrimento provocado pelo tratamento e pela própria evolução da enfermidade. Também é possível observar o comportamento oposto, quando há o distanciamento dos familiares do doente, deixando-o em contato direto com o médico responsável.

O tipo de dinâmica familiar repercute na relação do médico com o doente, seja pela ausência ou pelo excesso de participação no contexto da doença, fato que faz com que os oncologistas entrevistados sofram seus efeitos em ambos os casos. Isso ocorre porque a família do paciente foi citada como importante canal de comunicação do oncologista com o doente, pois são os familiares os principais conhecedores da personalidade, do estilo de enfrentamento e dos desejos do paciente. Paralelamente, a ausência da família exige do médico mais habilidade de escuta para identificar a adequação do conteúdo e do melhor momento para a comunicação ao doente.

Quando a família desenvolve uma atitude aparentemente protetora com relação ao doente, surge novo impasse na relação: o pedido para que a verdade do diagnóstico ou do prognóstico da doença não seja revelada. Essa solicitação da família ao médico, característica do século passado, quando se contava com poucas alternativas de cura para o câncer, ainda está presente nos dias atuais e mostra-se relevante no discurso dos entrevistados. O pedido, normalmente encenado pelo familiar mais próximo, representa o protótipo da manutenção do silêncio e do engano, quando por trás do paciente são feitos sinais negativos, mímico e postural, dirigidos ao oncologista para o estabelecimento da mentira ou do silêncio. Hoje, embora contando com diferentes recursos tecnológicos de comunicação, que podem fazer chegar ao médico o pedido antes mesmo do início da consulta e sem a presença do paciente, o conteúdo do pedido mantém-se o mesmo, consistindo em importante conflito para os oncologistas participantes da pesquisa.

Por um lado, o pedido da família pode se ajustar à opção do oncologista quando este, intencionalmente, prefere também adotar uma conduta enganosa, coadunando com suas próprias dificuldades no enfrentamento da situação. Por outro, quando o médico deseja estabelecer uma comunicação aberta e esclarecedora com todos os envolvidos, constata-se que a situação se caracteriza como conflito ético, demandando atenção especial no manejo dessa relação.

Apesar das dificuldades reveladas no discurso dos entrevistados, há pouca adesão ao uso de protocolos de revelação de diagnósticos e prognósticos. Entre os médicos que afirmaram conhecer o protocolo Spikes, o mais difundido protocolo de comunicação de más notícias na área da oncologia, observa-se pouca aceitação para sua aplicabilidade, com manifesta preocupação de que uma possível sistematização de procedimentos venha a se estabelecer nesse campo ${ }^{4}$. Nessa circunstância, o protocolo é entendido como um parâmetro, pois não possui condições de abarcar toda a complexidade relacional que o ato de comunicar más notícias envolve. O principal argumento contrário ao protocolo foi o de que cada comunicação implica em um encontro único, que se estabelece entre médicos, pacientes e familiares, originando respostas e situações absolutamente singulares, constituindo assim um cenário no qual não cabem condutas previamente padronizadas.

\section{Discussão}

As dificuldades e os conflitos éticos revelados nesta pesquisa são condizentes com os descritos na literatura e refletem uma realidade ainda presente em nossa sociedade 7,8,17,18. Dificuldades no campo da comunicação de diagnósticos e prognósticos de câncer contribuíram para a disseminação da "mentira piedosa" ou da "falsidade benevolente", termos empregados para sustentar, apesar da difícil justifi- 
cação moral, o engano na relação médico-paciente. Entre as principais consequências éticas desencadeadas estão o estímulo a atitudes paternalistas e protetoras para com o paciente e a consequente interferência no pleno exercício da autonomia do paciente ${ }^{12,16}$.

Impasses nesse campo interferem na qualidade da relação médico-paciente e podem provocar expectativas ilusórias nos pacientes e familiares, causando também sofrimento ao profissional. Além disso, impedimentos pessoais do médico na abordagem e no enfrentamento da morte podem levar a práticas de obstinação terapêutica, quando o médico insiste em tratamentos curativos apesar da doença já estar em fase terminal, momento em que seria necessária a indicação de condutas paliativas exclusivas ${ }^{19}$.

Frente aos problemas enfrentados, aspectos relacionados ao exercício da autonomia do paciente e à beneficência podem ser prejudicados. De acordo com a teoria dos quatro princípios, conforme descrita por Beauchamp e Childress ${ }^{12}$, a autonomia e a beneficência fazem parte dos quatro princípios morais que regem a ética biomédica. $O$ conceito de autonomia está diretamente relacionado à ideia de pertencimento do sujeito, devendo ser este o propulsor do próprio comportamento. Considera-se igualmente importante o princípio do respeito à autonomia do paciente. O qual se traduz em ações voltadas para a capacitação do paciente, provendoIhe condições para a tomada de decisões autônomas. Implica também em reconhecer o direito de o paciente ter opiniões e fazer escolhas baseadas em crenças e valores pessoais ${ }^{12}$.

No acompanhamento a pacientes com câncer o conhecimento acerca do real estado de saúde é fundamental para que possam participar ativamente do tratamento, compartilhando com a equipe médica das decisões tomadas nesse importante momento de suas vidas. Neste caso, o conhecimento acerca do prognóstico, bem como das possibilidades de tratamento, devem ser o quanto antes revelados e discutidos para que o paciente possa tomar suas próprias decisões e resolver as pendências que considerar necessárias.

Sendo o câncer, em geral, uma doença de rápida evolução e com progressiva fragilidade física do paciente, considera-se importante o investimento no desenvolvimento de um processo comunicacional que não se restrinja ao momento inicial de revelação do diagnóstico ou do prognóstico, mas que acompanhe o paciente e sua família, do início da doença até o seu desfecho, procurando manter um padrão de revelação de informações e de comunicação adequado às expectativas e desejos do paciente. A comunicação é uma habilidade que pode ser desenvolvida e aprimorada em programas de educação continuada. Por isso, atividades nesse campo devem ser estimuladas nos cursos de graduação e de treinamento médico. Atualmente, vem crescendo a gama de possibilidades de recursos didáticos para esse fim, inclusive por meio de programas de dramatização, otimizando a prática de ensino e a qualidade dos resultados obtidos ${ }^{20}$.

Estudo realizado nos Estados Unidos, entre 1999 e 2002, mostra que a informação dada pelo médico sobre a proximidade da morte acontece muito tardiamente, em média apenas um mês antes do fato concreto, e que familiares e pacientes, apesar da ambivalência dos seus desejos com relação à informação do prognóstico, consideram o conhecimento da verdade importante para a preparação para a morte ${ }^{18}$. Diante desse contexto, caracterizado pela enorme gama de dificuldades e conflitos quanto à forma, conteúdo e momento da comunicação, busca-se propor uma análise alternativa e complementar ao modelo protocolar de comunicação.

A utilização de protocolos específicos para a comunicação de más notícias, como o protocolo Spikes, deve ser utilizado como referência básica, conforme relatado pelos entrevistados, vez que não contempla a totalidade das demandas surgidas durante o processo comunicacional ${ }^{21}$. Assim, é relevante estimular o desenvolvimento de estudos no campo da bioética, que, mediante suas ferramentas teóricas, possam oferecer ao profissional a base moral norteadora para a tomada de decisão relacionada à comunicação.

Neste sentido, especial destaque é dado à importância do conhecimento da teoria das virtudes. Há, na atualidade, um movimento crescente de retomada de interesses e aplicabilidade da teoria das virtudes ao campo biomédico ${ }^{22}$. Parte desse interesse pode ser atribuído ao surgimento de uma ética contemporânea que, ante o crescente desenrolar de situações que reinam no campo da imprevisibilidade e da complexidade de fatores, prima pela reflexão e pela probabilidade, justificando desse modo o resgate de conceitos aristotélicos que podem oferecer fundamentação teórica consistente frente à resolução de conflitos éticos ${ }^{23}$.

Considerando-se que o ato de comunicar é uma atribuição médica, que como toda tarefa a ser realizada exige ponderação e preparo para sua boa execução, cabe destacar as orientações do bioeticista Diego Gracia ${ }^{24-26}$ que ressalta a importância do 
uso da prudência na prática médica. A prudência ganha relevo como virtude intelectual, conforme a teoria aristotélica das virtudes, necessária frente às situações em que a reflexão sobre os melhores meios se torna condição necessária para a realização de escolhas mais acertadas ${ }^{27}$.

De acordo com o pensamento aristotélico, as virtudes podem ser definidas, em oposição ao vício, como a disposição para fazer o bem. São nomeadamente divididas em dois tipos: virtude intelectual e virtude moral ou ética. As virtudes intelectuais tanto podem ser desenvolvidas quanto aprimoradas pela educação, bem como pelo tempo e experiência. São elas: a sabedoria, o entendimento e a prudência. As virtudes morais ou éticas, como a generosidade e a temperança, são consequências do hábito. A virtude no ser humano é o que o torna um bom ser humano e o que o faz desempenhar bem suas funções. $O$ conceito de virtude, como disposição que leva à determinação de escolhas, é acrescido à ideia de mediania, realçando a oposição em relação ao vício ${ }^{27}$.

$\mathrm{O}$ estado mediano encontra-se entre os dois extremos, ou entre os dois vícios, o do excesso e o da deficiência, sendo esse o ponto onde situamos as ações virtuosas e que constitui o caminho para chegarmos à compreensão da ideia da virtude da prudência como sendo a origem de todas as virtudes. Aristóteles situa a prudência como uma qualidade racional, sabedoria aplicável à vida prática ${ }^{27}$. A palavra prudência vem do latim prudentia, contração de providentia, que evoca a ideia de previdência, de saber eficaz ${ }^{28}$.

Na cultura ocidental, durante muito tempo, o termo esteve associado a sentidos pejorativos, de tal forma que na língua inglesa a tradução para a phronesis aristotélica é sabedoria prática, estando o significante prudência relacionado à astúcia e à ausência de qualquer tipo de compromisso ${ }^{23}$. $\mathrm{Na}$ língua portuguesa prudência é definida como: qualidade de quem age com moderação, comedimento, buscando evitar tudo o que se acredita ser fonte de erro ou de dano; ou ainda, como cautela e precaução ${ }^{29}$. A prudência é uma virtude que se refere às situações mutáveis e está associada à capacidade de deliberação.

Ao conotar o termo destaca-se contudo a importância da especificidade e da singularidade de cada situação, sem desprezar a visão de conjunto, do todo, que incidirá sobre a ação particular. A pessoa prudente é aquela capaz de bem deliberar sobre o que é bom e proveitoso em uma situação específica, seja esta de âmbito geral ou particular. Deliberar, por sua vez, é ato de investigação e de cál- culo, que direcionado a uma situação particular diz respeito ao acerto ou à exatidão na forma de pensar. A prudência, ocupando-se de situações particulares, agrega na deliberação os conhecimentos gerais e os particulares, a fim de alcançar o bem mais excelente em determinada situação ${ }^{26,27}$.

No campo de atuação da medicina, determinados traços de caráter do médico devem ser desenvolvidos. Dentre eles destacam-se: a compaixão, a benevolência, a honestidade, a coragem, a humildade intelectual e a fidelidade ${ }^{22,27}$. Essa pode ser considerada a diferença entre fazer o bem na medicina e ser um bom médico. O cumprimento das regras, dos princípios e dos deveres pode fazer com que o profissional exerça bem sua função, mas é no exercício das práticas virtuosas que se torna bom médico.

Nesse exercício, fica reservado à prudência o papel integrador dos aspectos intelectuais e morais de cada situação clínica, mediando e ordenando esses fatores. Diante da demanda por escolhas morais, a prudência funciona como virtude guia, propiciando a abertura e direcionando o caminho para a aplicabilidade das demais virtudes, de forma a evitar posições extremadas e alcançar a mediania das ações ${ }^{22,27}$.

Segundo autores bioeticistas 12,22,23, frente à revelação de uma notícia difícil é imprescindível a visão analítica da situação, considerando a totalidade dos aspectos relacionados ao paciente e sua situação clínica. A lealdade ao paciente é considerada fundamental para o alcance da confiança na relação; contudo, deve-se almejar a tomada de decisões prudentes, posto que, sendo cada situação única, não há garantia das consequências desencadeadas pela posição assumida. Nesse caso, existe a justificação concreta de que na singularidade de cada situação não há de fato decisões corretas, mas sim decisões prudentes quanto ao conteúdo e à qualidade da informação e ao momento da revelação ${ }^{23}$.

\section{Considerações finais}

Comunicar más notícias é tarefa de difícil manejo no campo da oncologia, desencadeando conflitos morais e questionamentos sobre a relação que se estabelece entre a revelação da verdade e os princípios da beneficência e da autonomia do paciente. De acordo com os dados levantados, a maior dificuldade enfrentada pelos entrevistados relaciona-se à singularidade de cada contexto e à imprevisibilidade das consequências das decisões tomadas pelo oncologista. Trata-se não apenas de situações 
únicas, permeadas de detalhes exclusivos em cada história, mas também de diferentes reações e capacidades de resposta de cada um dos envolvidos, ou seja, o médico, o paciente e sua família.

A relação entre o médico e o paciente, entendida como fundamental para a boa condução do tratamento, está ancorada no estilo e na qualidade da comunicação desenvolvida, sendo a participação familiar uma importante variável a ser considerada e adequadamente manejada pelo profissional durante todo o processo. No âmbito da comunicação médica, uma avaliação prudente, condizente com a ética das virtudes, pode harmonizar os valores morais, as regras e os princípios éticos em questão. Essa se constitui em importante referência, ratificando que, quanto aos aspectos relacionados à comunicação, apenas o conhecimento dos princípios éticos e o cumprimento das regras não fornecerá ao médico ingredientes suficientes para uma justificativa moral e para a fundamentação de seus atos ${ }^{17,18}$.

$\mathrm{O}$ ato de comunicar ao paciente e seus familiares prognósticos de doença avançada é acima de tudo uma decisão clínica que, como muitas outras assumidas diariamente na prática médica, exige do profissional reflexão, deliberação e ponderação dos fatos apresentados. Não havendo respostas a priori, é indispensável interpretar individualmente os sinais e as indicações dos pacientes. Trata-se da busca não necessariamente pela opção correta, mas sim por uma decisão prudente diante da situação apresentada, que contemple o contexto do paciente. Esta ideia coaduna-se com o objetivo da ética em geral e em particular com o da ética das virtudes, que deve ser o de evitar que as decisões sejam imprudentes, almejando assim o bem maior do paciente ${ }^{24,25}$.

Para evitar os extremos que podem variar da "mentira piedosa" à "verdade escancarada", recomenda-se a "verdade prudente", entendendo-a como a colocação da verdade possível e adequada às necessidades individuais de cada paciente. Para isso, deve-se priorizar e investir em programas de educação continuada voltados para a promoção e o aperfeiçoamento de habilidades de comunicação e de relacionamento interpessoal, que devem iniciar na graduação médica, associando-os ao estudo conceitual da bioética. Este parece ser o melhor caminho para fornecer ao médico a fundamentação teórica para as suas decisões e condutas ante os conflitos éticos enfrentados.

\section{Referências}

1. World Health Organization. Health topics - Cancer. [Internet]. (acesso 24 jun. 2013). Disponível: http://www.who.int/topics/cancer/en/

2. Sontag S. A doença como metáfora. Rio de Janeiro: Graal; 1984.

3. Geovanini FCM. Notícias que (des)enganam: o impacto da revelação do diagnóstico e as implicações éticas na comunicação de más notícias para pacientes oncológicos [dissertação]. Rio de Janeiro: Escola Nacional de Saúde Pública Sérgio Arouca/Fundação Oswaldo Cruz; 2011.

4. Baile WF, Buckman R, Lenzi R, Glober G, Beale EA, Kudelka AP. SPIKES - A six-step protocol for delivering bad news: application to the patient with cancer. Oncologist. 2000;5(4):302-11.

5. Hennezel M, Leloup J. A arte de morrer. Petrópolis: Vozes; 2005.

6. Kübler-Ross E. Sobre a morte e o morrer. São Paulo: WMF Martins Fontes; 2005.

7. Trindade ES, Azambuja LEO, Andrade JP, Garrafa V. O médico frente ao diagnóstico e prognóstico do câncer avançado. Rev. Assoc. Med. Bras. 2007;53(1):68-74.

8. Díaz FG. Comunicando malas noticias en Medicina: recomendaciones para hacer de la necessidad virtud. Med Intensiva. 2006;30(9):452-9.

9. Nuland SB. Como morremos: reflexões sobre o último capítulo da vida. Rio de Janeiro: Rocco; 1995.

10. Ariès P. História da morte no Ocidente. Rio de Janeiro: Francisco Alves; 1977.

11. Elias N. A solidão dos moribundos seguido de "envelhecer e morrer". Rio de Janeiro: Jorge Zahar; 2001.

12. Beauchamp TL, Childress JF. Princípios de ética biomédica. São Paulo: Loyola; 2002.

13. Franco F. Humanização na saúde: uma questão de comunicação. In: Epstein I, organizador. A comunicação também cura na relação entre médico e paciente. São Paulo: Angellara; 2006. p. 149-63.

14. Conselho Federal de Medicina. Resolução CFM n 1.931, de 17 de setembro de 2009. Aprova o novo Código de Ética Médica. Diário Oficial da União. 24 set 2009;(183):seção I, p. 90-2.

15. Minayo MCS. O desafio do conhecimento: pesquisa qualitativa em saúde. São Paulo: Hucitec; 2008.

16. Pan Chacon JP, Kobata CM, Liberman SPC. A mentira piedosa para o canceroso. Rev. Assoc. Med. Bras. 1995;41(4):274-6.

17. Adler DD, Riba MB, Eggly S. Breaking bad news in the breast imaging setting. Acad Radiol. 2009.16(2):130-5. 
18. Cherlin E, Fried T, Prigerson HG, Schulman-Green D, Johnson-Hurzeler R, Bradley EH. Communication between physicians and family caregivers about care at the end of life: when do discussions occur and what is said? J Palliat Med. 2005;8(6):1176-85.

19. Menezes RA. Em busca da boa morte: antropologia dos cuidados paliativos. Rio de Janeiro: Garamond/Fiocruz; 2004.

20. Bonamigo EL, Destefani AS. A dramatização como estratégia de ensino da comunicação de más notícias ao paciente durante a graduação médica. Rev. bioét. (Impr.). 2010;18(3):725-42.

21. Burlá C, Py L. Peculiaridades da comunicação ao fim da vida de pacientes idosos. Bioética. 2005;13(2):97-106.

22. Pellegrino ED, Thomasma DC. The virtues in medical practice. New York: Oxford University Press; 1993.

23. Gracia D. Pensar a bioética: metas e desafios. São Paulo: Loyola; 2010

24. Gracia D. O importante são decisões éticas prudentes. In: Oselka G, coordenador. Entrevistas exclusivas com grandes nomes da bioética (estrangeiros). São Paulo: Cremesp; 2009. p. 59-66.

25. Gracia D. Cuidado com o fundamentalismo bioético. In: Oselka G, coordenador. Entrevistas exclusivas com grandes nomes da bioética (estrangeiros). São Paulo: Cremesp; 2009. p. 67-74.

26. Gracia D. La deliberación moral: el método de la ética clínica. Med Clin (Barc). 2001;117(1):18-23.

27. Aristóteles. Ética a Nicômaco. São Paulo: Edipro; 2007.

28. Aubenque P. A prudência em Aristóteles. In: Lopes M, tradutor. 2a ed. São Paulo: Paulus; 2008.

29. Ferreira ABH. Dicionário Aurélio da língua portuguesa. Curitiba: Positivo; 2007.

\section{Participação das autoras}

Fátima Geovanini redigiu o artigo e Marlene Braz realizou a revisão crítica. 